\title{
Kinetics of pyrolysis and combustion of pine needles and cones
}

\author{
R. Font*, J.A. Conesa, J. Moltó, M. Muñoz \\ Department of Chemical Engineering, University of Alicante, Apto 99, E-03080 Alicante, Spain
}

\section{A R T I C L E I N F O}

Article history:

Received 30 June 2008

Received in revised form 30 October 2008

Accepted 6 November 2008

Available online xxx

\section{Keywords:}

Pine needle

Pine cone

Pyrolysis

Combustion

Kinetics

\begin{abstract}
A B S T R A C T
A wide kinetic study has been carried out under different conditions in TG and TG-MS for each material, at different operating conditions. Runs were carried out at three different atmospheres: $\mathrm{N}_{2}, \mathrm{~N}_{2}: \mathrm{O}_{2} 4: 1$ and $\mathrm{N}_{2}: \mathrm{O}_{2} 9: 1$. In addition to the dynamic runs carried out at constant heating rate, other runs were performed in an isothermal regime (constant heating rate until the set temperature is reached and then the set temperature is maintained constant).

In addition, a study of the thermal decomposition for both materials was also carried out in a dynamic run using TG-MS in order to observe the evolution of the major compounds and to discuss the information that could be obtained.

From the overall analysis of the data, schemes of reactions and kinetic values were calculated by integration of the differential equations and minimizing the squared differences between the experimental and calculated values. It is important to emphasise that the same set of parameters is proposed for the runs for each material, and depends on neither the heating rate in dynamic runs nor whether the run is carried out in a dynamic or isothermal mode.
\end{abstract}

(c) 2008 Elsevier B.V. All rights reserved.

\section{Introduction}

Pine needles and cones are biomass that can be of use as fuel themselves or forming fuel briquettes. On the other hand, thermal decomposition takes place under poor combustion conditions in forest fires, and every year wildfires damage vast areas.

Thermal degradation of pine cone and pine needle was the subject of interest of research, focusing on some aspects considered as follows; there are some studies concerning the influence of additives on the pyrolysis of pine needles. Liodakis et al. [1] tested the influence of several fire retardants on the pyrolysis of cellulose and pine needles on DSC, whereas Pappa et al. [2] studied the effects of retardants with TG-MS, and Statheropoulos et al. [3] determined some volatile compounds with the same materials using several analytical methods including Py-GCMSD.

Lee et al. [4] determined the optimum conditions for the analysis of volatile component pine needles by double-shot pyrolysis-gas chromatography.

Leoni et al. [5] studied the dehydration kinetics of Pinus Pinaster needles from DSC curves using different known mathematical methods in nitrogen and in air.

\footnotetext{
* Corresponding author at: Chemical Engineering Department, University of Alicante, P.O. Box 99, 03080 Alicante, Spain. Tel.: +34 96590 3546; fax: +34965903826.

E-mail address: rafael.font@ua.es (R. Font).
}

On the other hand, Senneca [6] studied the pyrolysis kinetics of pine seed shells from TG and DTG data, considering only one reaction and proposing values for the activation energy, reaction order and pre-exponential factor.

Haykiri-Acma and Yaman [7] studied the gasification of pine cone and other biomass material, obtaining the gasification yields at different temperature intervals and proposing a value for the apparent activation energy of $33.8 \mathrm{~kJ} / \mathrm{mol}$ with a $1: 1$ nitrogen:steam ratio of the atmosphere.

Leoni et al. [8] studied the kinetics of the combustion of pine needles by DSC and considered two fractions in the decomposition.

No other kinetic models have been found in literature for combustion at normal conditions and in poor oxygen concentration when pyrolysing or burning pine needles or cones.

The objective of this study has been the proposal of kinetic models valid in different operating conditions, both in pyrolysis and combustion. These kinetic models are useful for understanding the behavior of the materials in reactors and furnaces, and also when burning these materials in different atmospheres and temperature conditions.

\section{Experimental}

\subsection{Raw material}

The samples employed in this study were cone and needle of Mediterranean Pine. Prior to the runs, the samples were milled to an average size of $1 \mathrm{~mm}$. Table 1 presents the elemental and 
Table 1

Characteristics of the materials used.

\begin{tabular}{lll}
\hline & Pine needles & Pine cones \\
\hline $\begin{array}{l}\text { Moisture (wt. \%) } \\
\text { Analysis on dry basis }\end{array}$ & 12 & 8.9 \\
C (wt.\%) & 50.4 & \\
$\mathrm{H}$ (wt.\%) & 6.5 & 54.2 \\
$\mathrm{~N}$ (wt.\%) & 0.8 & 6.8 \\
$\mathrm{~S}$ (wt.\%) & 0.01 & 0.3 \\
Ash content (wt.\%) & 4.5 & - \\
O\% by difference (wt.\%) & 37.9 & 0.8 \\
Cl (wt.\%) & 0.22 & 38.7 \\
Net calorific value (kJ kg ${ }^{-1}$ ) & 20,138 & 0.17 \\
Ethanol extracts & 18.2 & 18,782 \\
Hemicellulose & 17.7 & 7.3 \\
Cellulose & 38.7 & 21.7 \\
Lignin & 20.1 & 39.3 \\
\hline
\end{tabular}

moisture analysis of the materials studied. Elemental analysis of the major components was carried out in a Perkin-Elmer 2400, the calorific value was determined in an AC-350 calorimetric bomb from Leco Corporation and the ash residue was obtained by calcinations at $850{ }^{\circ} \mathrm{C}$. Moisture was determined by the weight loss at $105{ }^{\circ} \mathrm{C}$ for $12 \mathrm{~h}$. Chlorine was measured using an automatic sequential spectrometer X-ray Fluorescence model TW 1480 that gives semi-quantitative results. Ethanol-solubilized, hemicellulose, cellulose and lignin contents were determined for both materials [9-12]. It can be observed that the ultimate analysis (C, $\mathrm{H}, \mathrm{S}, \mathrm{N}, \mathrm{Cl}$ ) gives similar results for both compounds, although there is a considerable ash percentage in the case of pine needles, probably due to the presence of inert material in the sample which causes a net calorific value lower than that of pine cones. On the other hand, the content of lignin in the pine cones is higher than that of pine needles, which is logical considering the cementing properties of lignin. On the contrary, the ethanol extract content of pine needles is higher than that of pine cones due to the different nature of both materials.

\subsection{Thermobalance}

Runs for pyrolysis were carried out on a Mettler Toledo thermobalance model TGA/SDTA851e/LF/1600. This equipment has a horizontal furnace and a parallel-guided balance. In this way, positioning of the sample has no influence in the measurement,

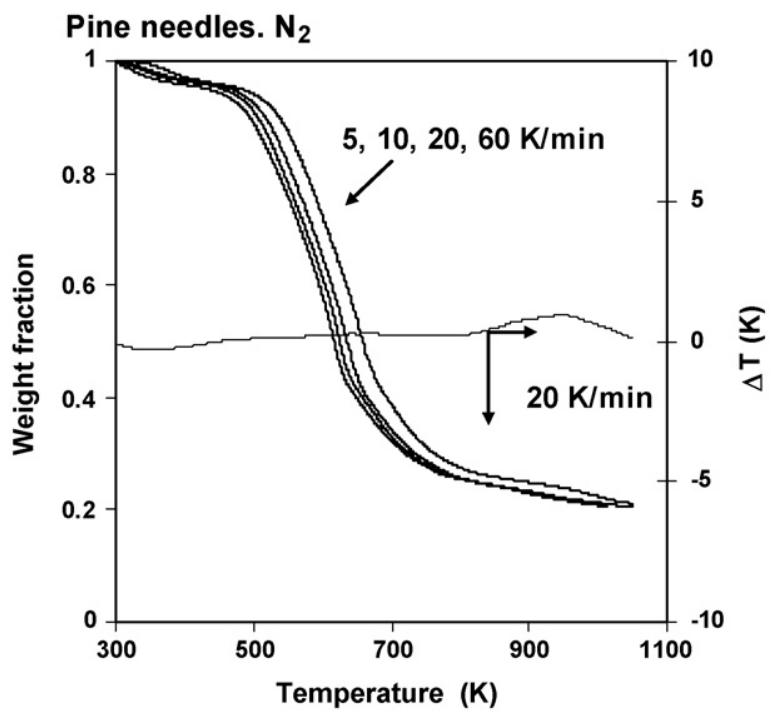

Fig. 1. Pine needle pyrolysis at several heating rates: $5,10,20$ and $60 \mathrm{~K} \mathrm{~min}^{-1}$. Experimental curves (the calculated curves overlap the experimental ones). and flow gas perturbation and thermal buoyancy are minimized. The sample temperature was measured with a sensor directly attached to the sample holder.

For the pyrolysis runs, the atmosphere used was nitrogen. Two atmospheres were used for the combustion runs: $\mathrm{N}_{2}: \mathrm{O}_{2} 4: 1$ and $\mathrm{N}_{2}: \mathrm{O}_{2}$ 9:1. The flow rate was $100 \mathrm{ml} \mathrm{min}^{-1}$.

Dynamic experiments were carried out at different heating rates between 5 and $60{ }^{\circ} \mathrm{C} \mathrm{min}{ }^{-1}$, from the initial temperature up to $1073 \mathrm{~K}$, including in this way the entire range of decomposition. Isothermal experiments started with a constant heating rate until the desired temperature was reached, the final temperature was maintained constant throughout the pyrolysis or combustion process and the experiment was considered to be finished when the weight loss rate was very small. The mass of sample used was around $5 \mathrm{mg}$, and under these conditions the heat transfer limitations can be neglected.

A pyrolysis run with a heating rate of $5{ }^{\circ} \mathrm{C} \mathrm{min}^{-1}$ using Avicel PH-105 microcrystalline cellulose was done. The kinetic values obtained showed good agreement with the results presented by Grønli et al. [13] in their round-robin study of cellulose pyrolysis kinetics by thermogravimetry. This experiment was used to check the good performance of the thermobalance.

The TG-MS runs were carried out in a TGA/SDTA851e/LF/1600 with TG-ATD coupled to a Thermostar GSD301T Pfeiffer Vacuum MS apparatus using helium as carrier gas and with the following operating conditions: mass sample around $10 \mathrm{mg}$, heating rate $30{ }^{\circ} \mathrm{C} / \mathrm{min}$, ionization $70 \mathrm{eV}$, SIR detection of several ions: 4, 13-18, 25-32, 35-46 in one run and the following ions in another run: 4 , $32,43-46,50-52,55-58,60,65,68,73,78,91,96,105,106$. It was tested that the very small oxygen concentration in the helium used can cause a small oxidation of the sample and/or the volatiles evolved in the pyrolysis run. The response of the different ions was divided by that of helium $(m / z=4)$ and subtracted from that corresponding to the beginning of the run.

\section{Pyrolysis: results and discussion}

\subsection{Pyrolysis: experimental results}

Fig. 1 shows the experimental TG plots for pine needle pyrolysis (nitrogen) at heating rates of $5,10,20$ and $60 \mathrm{~K} \mathrm{~min}^{-1}$. In the figures, the weight fraction represents the residual mass fraction of the solid (including residue formed and non-reacted initial solid). The value of increment of temperature, corresponding to the DTA,

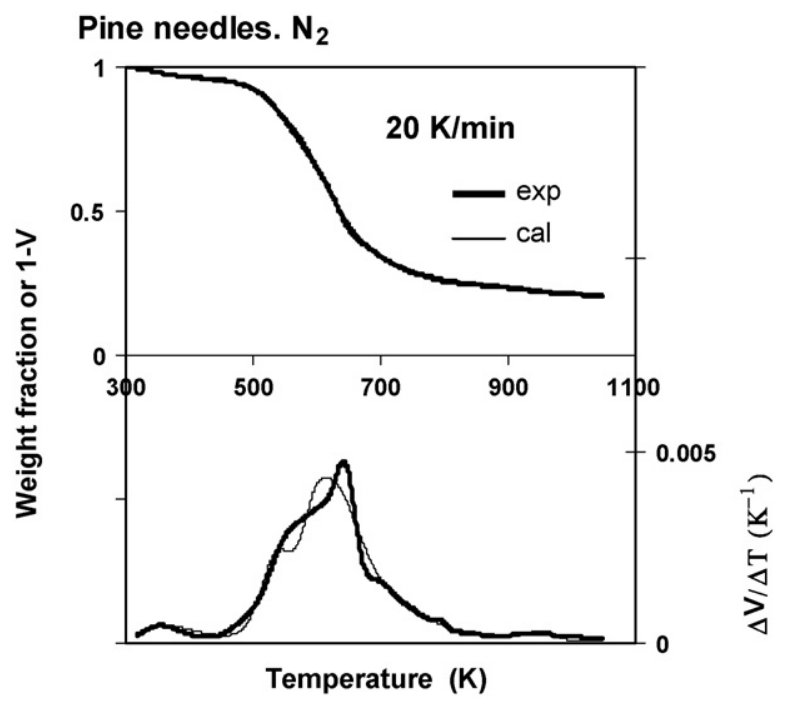

Fig. 2. Weight fraction and its derivative from a pine needle pyrolysis run. 


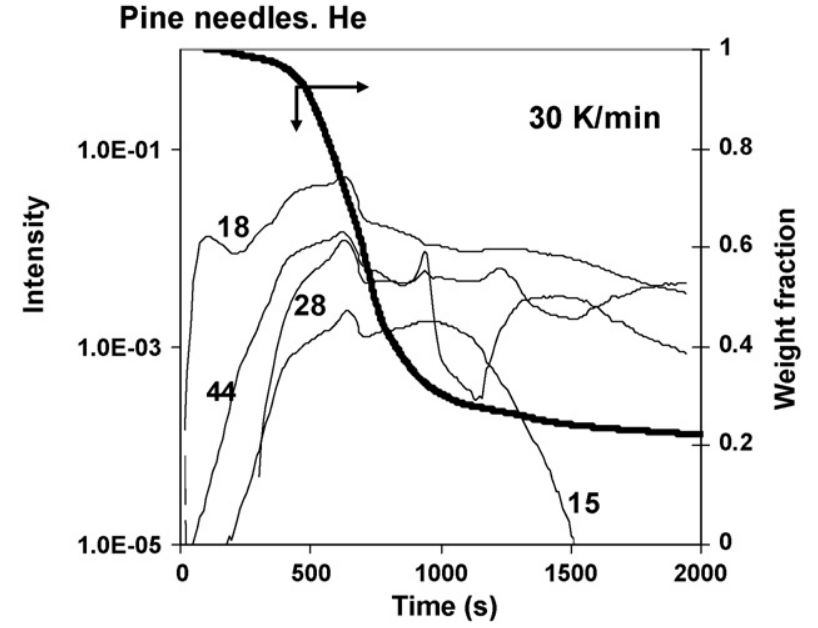

Fig. 3. Intensities of the ions $15\left(\mathrm{CH}_{4}\right), 18\left(\mathrm{H}_{2} \mathrm{O}\right), 28(\mathrm{CO})$ and $44\left(\mathrm{CO}_{2}\right)$ in a pyrolysis TG-MS run (He atmosphere) of pine needles.

for a run is also plotted in a convenient scale, from $-10 \mathrm{~K}$ which represents a strong endothermic process to $10 \mathrm{~K}$ corresponding to a strong exothermic process. It can be observed that there is only a slight endothermic process at the first part of sample, due mainly to the vaporization of the humidity, and a light exothermic process at the last part of decomposition.

Fig. 2 shows the DTG curve for a run, in order to observe the fractions that can be considered in the decomposition of the pine needles. It can be deduced that there is an initial small peak, a wide band and finally another small peak. Considering the normal shapes of the peaks, the wide band could be the sum of three peaks, the first two of them very close and the third one being a wide peak.

Fig. 3 shows the intensities of some ions in the MS-TG run (pine needles), corresponding to $\mathrm{H}_{2} \mathrm{O}(\mathrm{m}+18), \mathrm{CO}_{2}(\mathrm{~m}+44), \mathrm{CO}(\mathrm{m}+28)$ and $\mathrm{CH}_{4}\left(\mathrm{~m}+15\right.$ corresponding to $\left.\mathrm{CH}_{3}+\right)$. The variation of the weight loss can also be observed. For the water, there is an initial peak due to the humidity of the sample, and then the overlapped decomposition of many fractions that leads to the formation of water. At the end of the test, the small concentration of oxygen in

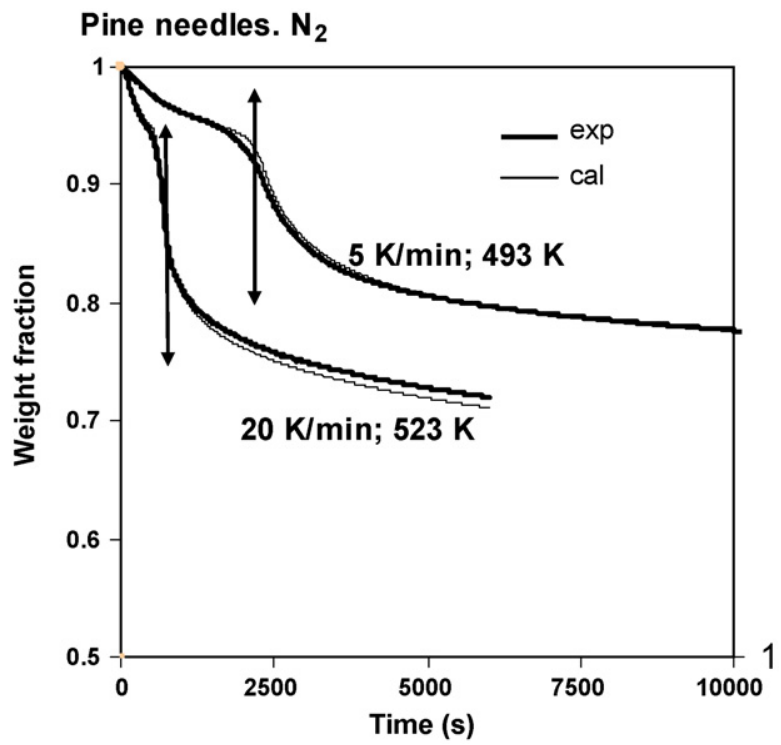

Fig. 4. Isothermal pine needle pyrolysis. Experimental and calculated curves.
Pine cones. $\mathbf{N}_{2}$

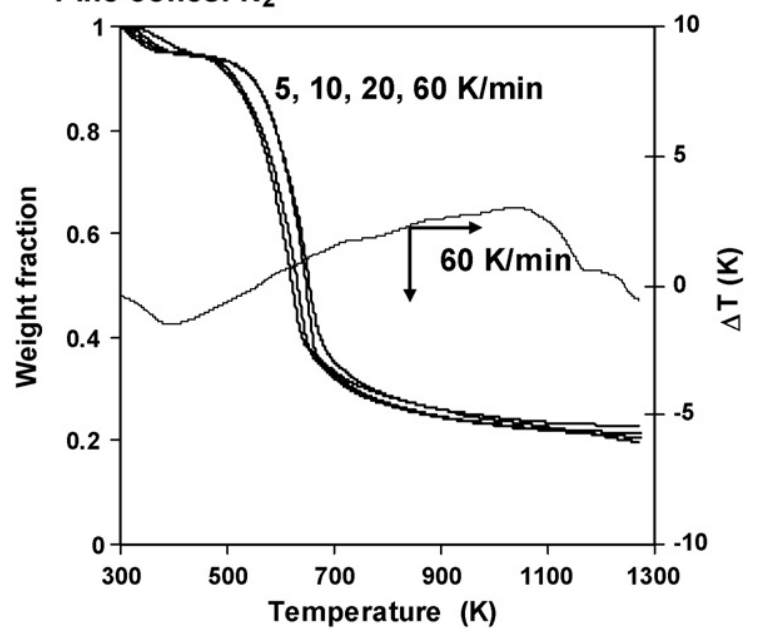

Fig. 5. Pine cone pyrolysis at several heating rates: $5,10,20$ and $60 \mathrm{~K} \mathrm{~min}^{-1}$. Experimental curves (the calculated curves overlap the experimental ones).

the helium stream could be responsible of a small formation of water as a consequence of the combustion of the char residue.

Two isothermal experiments were carried out for the pyrolysis of the sample, and the corresponding data are shown in Fig. 4. These experiments started with a heating rate until the desired temperature was reached, the final temperature was maintained constant throughout the pyrolysis process. In the figures corresponding to the isothermal runs, the double arrow separates the first part corresponding to the constant heating constant period from the second part with a constant temperature. Note that the final value of mass loss of the run depends on the period of time considered, and logically is lower than that obtained at infinite time.

Fig. 5 shows the experimental TG plots for pine cone pyrolysis (nitrogen) at heating rates of $5,10,20$ and $60 \mathrm{~K} \mathrm{~min}^{-1}$. The $\Delta T$ corresponding to the DTA analysis is also plotted and an initial small endothermic process is observed (due also to the vaporization of the humidity), whereas a small, but significant exothermic process is observed in the last part of decomposition. The same effect is clearly observed in the $20 \mathrm{~K} / \mathrm{min}$ run.

Fig. 6 shows the weight fraction and its derivative for a dynamic run with pine cones, indicating that there is an initial small

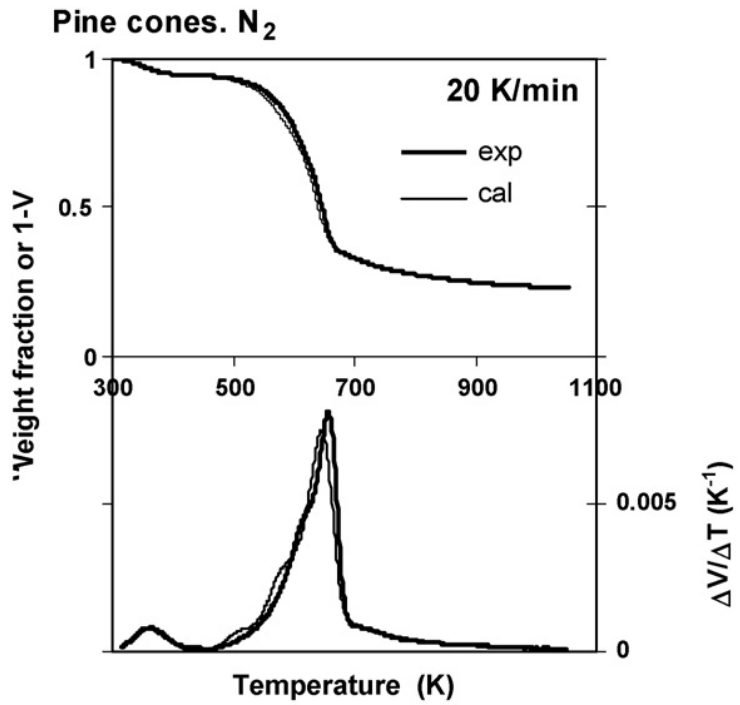

Fig. 6. Weight fraction and its derivative from a pine cone pyrolysis run. 


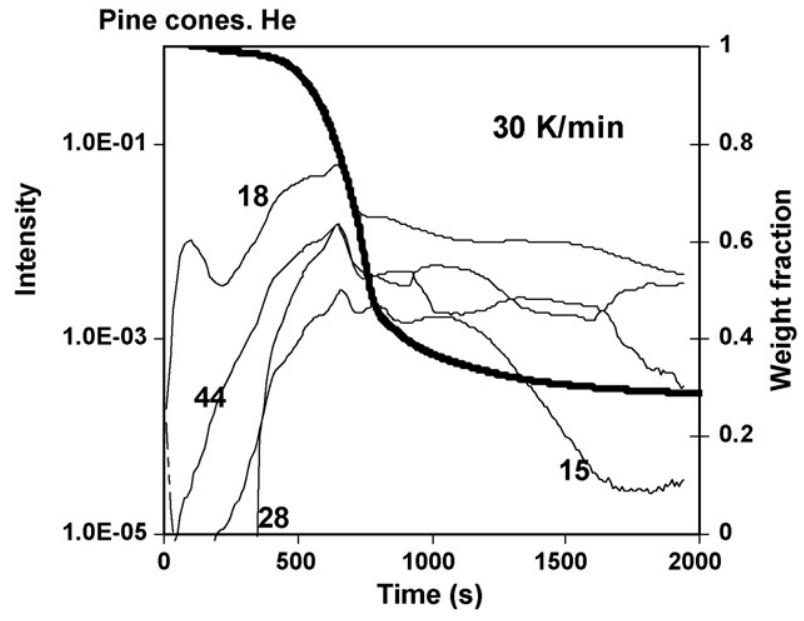

Fig. 7. Intensities of the ions $15\left(\mathrm{CH}_{4}\right), 18\left(\mathrm{H}_{2} \mathrm{O}\right), 28(\mathrm{CO})$ and $44\left(\mathrm{CO}_{2}\right)$ in a pyrolysis TG-MS run (He atmosphere) of pine cones.

evolution of volatiles (mainly water) a wide curve, that could be the sum of two peaks (due to the differences with respect to a normal peak), and a fourth peak at the tail of the curve.

The variation of the ion intensities of a dynamic TG-MS run (pine cones) is plotted vs. time in Fig. 7, indicating the evolution of water at the beginning of the run and then a wide band, sum of the decomposition of many fractions.

Fig. 8 shows the experimental results of four isothermal runs (pine cones), obtained with different operating conditions. The final residue is different in each run depending on the operating temperature, indicating that there are some fractions that only decompose at high temperatures.

From the previous results, TG, DTG and MS-TG, it seems reasonable that for obtaining good correlation models, five fractions and four fractions must be considered in the pyrolysis of pine needles and pine cones respectively.

\subsection{Pyrolysis model}

The kinetic model proposed for the pyrolysis could be interpreted considering each waste formed by four independent parts, each one following an independent reaction, as follows:

$w_{\mathrm{s}_{10}}$ Solid $_{1} \stackrel{1}{\longrightarrow}\left(w_{\mathrm{s}_{10}}-v_{1 \infty}\right)$ Char $_{1}+v_{1 \infty}$ Volatiles $_{1}$

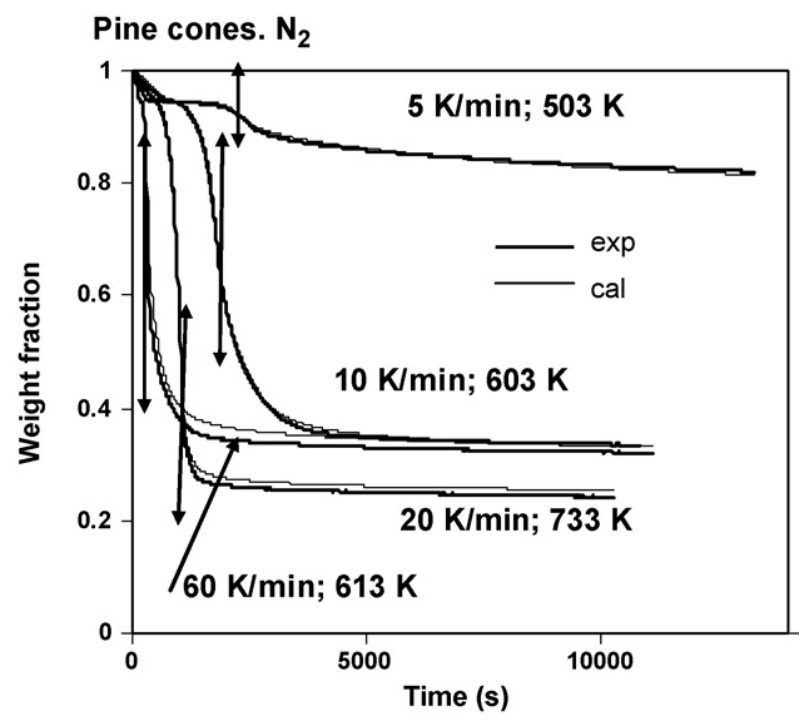

Fig. 8. Isothermal pine cone pyrolysis. Experimental and calculated curves.

$$
\begin{gathered}
w_{\mathrm{s}_{20}} \text { Solid }_{2} \stackrel{2}{\longrightarrow}\left(w_{\mathrm{s}_{20}}-v_{2 \infty}\right) \text { Char }_{2}+v_{2 \infty} \text { Volatiles }_{2} \\
w_{\mathrm{s}_{30}} \text { Solid }_{3} \stackrel{3}{\longrightarrow}\left(w_{\mathrm{s}_{30}}-v_{3 \infty}\right) \text { Char }_{3}+v_{3 \infty} \text { Volatiles }_{3} \\
w_{\mathrm{s}_{40}} \text { Solid }_{4} \stackrel{4}{\longrightarrow}\left(w_{\mathrm{s}_{40}}-v_{4 \infty}\right) \text { Char }_{4}+v_{4 \infty} \text { Volatiles }_{4}
\end{gathered}
$$

For the pyrolysis of pine needles, a fifth fraction is considered, but the volume of volatiles evolved from this fraction is very small and could be negligible. Nevertheless, this small fraction has also been considered:

$w_{\mathrm{s}_{50}}$ Solid $_{5} \stackrel{5}{\longrightarrow}\left(w_{\mathrm{s}_{50}}-v_{5 \infty}\right)$ Char $_{5}+v_{5 \infty}$ Volatiles $_{5}$

In the previous reactions, Solid $_{1}$, Solid $_{2}, \ldots$, Solid $_{5}$ refer to different fractions or components of the original material, "Volatiles $i$ " are the gases and condensable volatiles evolved in the corresponding reactions $(i=1-5)$, and "Char ${ }_{i}$ " is the char formed in the decomposition of each $\operatorname{Solid}_{i}(i=1-5)$. On the other hand, the small letters represent the yield coefficients representative of each reaction and consequently, it is considered not changing with time and with the extension of the reaction. Moreover, each fraction has a yield coefficient that represents the maximum mass fractions obtainable by each reaction. In this way, $v_{i \infty}$ is the yield coefficient for the Volatiles $_{i}$ and $V$ is the mass fraction of volatiles.

The concept of the conversion degree for each reaction is defined as the ratio between the mass fraction of solid reacted at any time $\left(w_{s_{i 0}}-w_{s_{i}}\right)$ and the corresponding initial fraction of this component $w_{s_{i 0}}$, or the ratio between the mass fraction of volatiles obtained at any time during which the reaction is taking place $\left(V_{i}\right)$ and the corresponding yield coefficient or the mass fraction of volatiles at infinite time:

$\alpha_{i}=\frac{w_{s_{i 0}}-w_{s_{i}}}{w_{\mathrm{s}}}=\frac{V_{i}}{v_{i \infty}}, \quad i=1-5$

On the other hand, it can be stated that

$\sum_{i=1}^{5} w_{s_{i 0}}=1$

Considering the mass balance between products and reactants and the conversion degrees, the kinetic equations for the pyrolysis runs can be expressed as follows:

$$
\begin{aligned}
-\frac{\mathrm{d}\left(w_{\mathrm{s}_{i}} / w_{\mathrm{s}_{\mathrm{i} 0}}\right)}{\mathrm{d} t} & =\frac{\mathrm{d}\left(V_{i} / V_{i \infty}\right)}{\mathrm{d} t}=\frac{\mathrm{d} \alpha_{i}}{\mathrm{~d} t}=k_{i}\left(\frac{w_{\mathrm{s}_{i}}}{w_{\mathrm{s}_{i 0}}}\right)^{n_{i}}=k_{i}\left(1-\alpha_{i}\right)^{n_{i}} \\
& =k_{i}\left(1-\frac{V_{i}}{v_{i \infty}}\right)^{n_{i}}
\end{aligned}
$$

with the kinetic constants following the Arrhenius equation:

$k_{i}=k_{i 0} \exp \left(-\frac{E_{i}}{R T}\right), \quad i=1-5$

By integration of these equations, it is possible to calculate $\alpha_{1}$ to $\alpha_{5}$ at each time if the temperature program is known; the relationship between $\alpha_{i}$ values and the weight fraction measured in the thermobalance $(w)$ is related with the volatiles obtained $(V)$ by

$w=1-V=1-\left(v_{1 \infty} \alpha_{1}+v_{2 \infty} \alpha_{2}+v_{3 \infty} \alpha_{3}+v_{4 \infty} \alpha_{4}+v_{5 \infty} \alpha_{5}\right)$

\subsection{Pyrolysis: kinetic parameters}

In order to obtain a single set of parameters for the pyrolysis of each material, for each waste, the dynamic runs and the isothermal 
runs were correlated to the same set of parameters. The calculated values were obtained by integration of the differential equations presented in the kinetic model, by the Euler method, but considering and testing that the intervals of time are small enough so the errors introduced are negligible. The optimization method of the function Solver in a spreadsheet Excel was used to minimize the differences between experimental and calculated weight loss and their derivatives. In the correlation of the data, the variation of the temperature read by the thermocouple has been taken into account. That means that during the constant heating rate period, the increasing temperature and the time are considered, whereas for the constant temperature period, this temperature and the time are used for the integration of the differential equations.

The objective function (OF) to minimize was the sum of the square differences between experimental and calculated weight loss values $V$ and their derivatives multiplied by a factor in order to make the two terms similar, although this factor was changed in order to obtain acceptable correlations:

$\mathrm{OF}=\sum_{m=1}^{M} \sum_{j=1}^{N}\left(V_{m, j}^{\exp }-V_{m, j}^{\mathrm{cal}}\right)^{2}+$ factor $\sum_{m=1}^{M} \sum_{j=1}^{N}\left(\frac{\mathrm{d} V_{m, j}^{\mathrm{exp}}}{\mathrm{d} t}-\frac{\mathrm{d} V_{m, j}^{\mathrm{cal}}}{\mathrm{d} t}\right)^{2}$

where $M$ is the number of runs and $N$ is the number of points in each run.

The model validity has been tested calculating the variation coefficient (VC):

$\mathrm{VC}=\frac{\sqrt{\mathrm{OF} /\left(N_{\mathrm{total}}-P\right)}}{\overline{V_{\mathrm{exp}}}} \times 100$

where $N_{\text {total }}$ and $P$ are the number of data and parameters fitted, respectively, and $\overline{V_{\exp }}$ is the average of the experimental values of fraction mass corresponding to the volatiles evolved. In order to scale parameter fitting, and according to the procedure suggested by Martín-Gullón et al. [14], the optimization is performed in terms of a 'comparable kinetic constant' $K_{i}^{*}$ (calculated for non-reacted fraction 0.64) instead of optimizing $k_{0 \mathrm{i}}$. This constant is calculated at a temperature around the maximum decomposition rate $\left(T_{\max }\right)$. Value 0.64 was obtained from the optimization program for decreasing the great interrelation between the pre-exponential factor, the apparent energy and reaction order. Since $K_{i}^{*}, E_{i}$ and $n_{i}$ are optimised, the pre-exponential factor $k_{0 i}$ is deduced from the following expression:

$K_{i}^{*}=k_{i}(0.64)^{n_{i}}=k_{0 i} \exp \left(-\frac{E_{i}}{R T_{\max }}\right)(0.64)^{n_{i}}$

Table 2 shows the set of parameters optimized for both wastes, where the variation coefficients VC are very small. The calculated curve variations are also plotted in Figs. 2, 4, 6 and 8, being very close and/or overlapping the experimental curves. The calculated values corresponding to the dynamic runs shown in Figs. 1 and 5 have not been plotted because they overlap the experimental ones.

In view of Table 2 , some interesting aspects can be emphasized and are common for both wastes.

There is an initial small fraction (volatile fraction around 0.06), whose volatiles evolved around $300-370 \mathrm{~K}$, with a small apparent activation energy (43-44 kJ/mol), corresponding mainly to the humidity of the sample. This small value of activation energy is similar to $58.2 \mathrm{~kJ} / \mathrm{mol}$ proposed by Leoni et al. [5], in the dehydration kinetics of Pinus pinaster.

After the evolution of volatiles corresponding to the first fraction, a second fraction decomposes at 470-600 K, with apparent activation energy around $130-140 \mathrm{~kJ} / \mathrm{mol}$, and probably corresponds mainly to the hemicellulose. These values are close to
Table 2

Kinetic parameters obtained for the pyrolysis of pine needles and pine cones $\left(k_{i o}\right.$ and $k_{i}$ in $\mathrm{s}^{-1}$ and $E_{i}$ in $\mathrm{kJ} \mathrm{mol}^{-1}$ ).

\begin{tabular}{|c|c|c|}
\hline & Pine needle (5 reactions) & Pine cone ( 4 reactions) \\
\hline \multicolumn{3}{|c|}{$w_{s_{i 10}}$ Solid $_{\mathrm{i}} \stackrel{\mathrm{i}}{\longrightarrow}\left(w_{s_{i 0}}-v_{i \infty}\right)$ Char $_{\mathrm{i}}+v_{i \infty}$ Volatiles $_{i}$} \\
\hline$V_{1}$ & 0.06 & 0.05 \\
\hline$k_{10}$ & $1.985 E+04$ & $3.054 \mathrm{E}+04$ \\
\hline$E_{1}$ & 43.07 & 43.54 \\
\hline$n_{1}$ & 4.20 & 1.30 \\
\hline$V_{2}$ & 0.19 & 0.06 \\
\hline$k_{20}$ & $5.838 \mathrm{E}+11$ & $8.500 \mathrm{E}+11$ \\
\hline$E_{2}$ & 137.18 & 132.36 \\
\hline$n_{2}$ & 2.89 & 3.70 \\
\hline$V_{3}$ & 0.40 & 0.28 \\
\hline$k_{30}$ & $5.771 \mathrm{E}+18$ & $8.920 \mathrm{E}+14$ \\
\hline$E_{3}$ & 233.32 & 203.39 \\
\hline$n_{3}$ & 7.73 & 1.13 \\
\hline$V_{4}$ & 0.14 & 0.40 \\
\hline$k_{40}$ & $3.403 \mathrm{E}+14$ & $2.656 \mathrm{E}+15$ \\
\hline$E_{4}$ & 197.31 & 190.64 \\
\hline$n_{4}$ & 3.58 & 8.69 \\
\hline$V_{5}$ & 0.01 & \\
\hline$k_{50}$ & $1.615 E+21$ & \\
\hline$E_{5}$ & 415.70 & \\
\hline$n_{5}$ & 1.00 & \\
\hline VC (\%) & 1.7 & 3.3 \\
\hline
\end{tabular}

the value $110 \mathrm{~kJ} / \mathrm{mol}$ proposed for the hemicellulose in literature [15].

The following fraction decomposed in the range $550-700 \mathrm{~K}$ with an apparent activation energy around $200-240 \mathrm{~kJ} / \mathrm{mol}$. It has been suggested that cellulose decomposes in the range $300-400{ }^{\circ} \mathrm{C}$ with apparent activation energy around 150-250 kJ/mol [13,1618].

There is a fourth fraction that decomposes in a wide temperature interval (550-800 K), with apparent activation energy around $190-200 \mathrm{~kJ} / \mathrm{mol}$ that corresponds mainly to lignin. In literature, the values of activation energy proposed vary significantly between themselves, but it is indicated that the decomposition takes place in an extensive temperature interval. Gr $\varnothing$ nly et al. [19] studied the devolatilization kinetics of wood, and deduced the following values of activation energies for first-

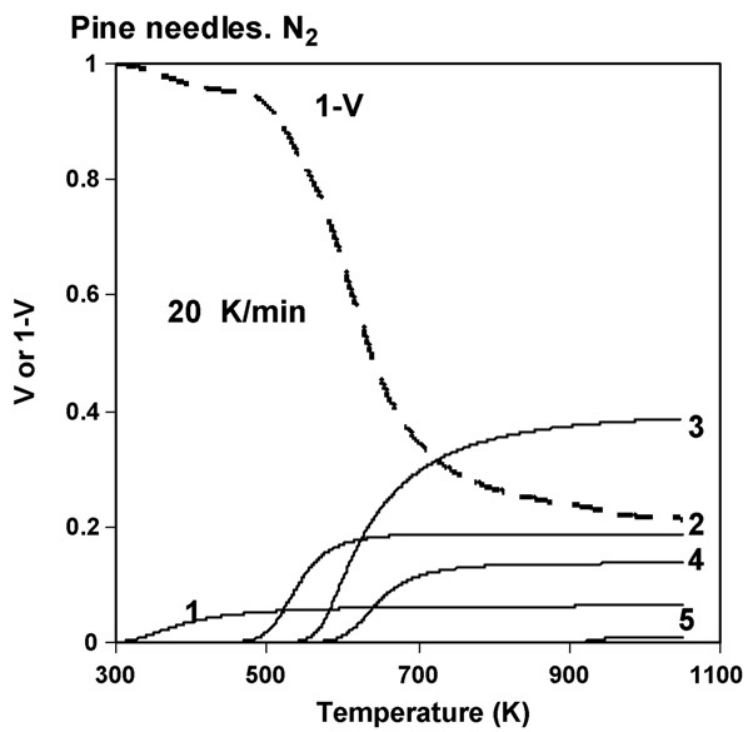

Fig. 9. Evolution of the mass fraction of volatiles for each reaction in a pine needle pyrolysis run. 


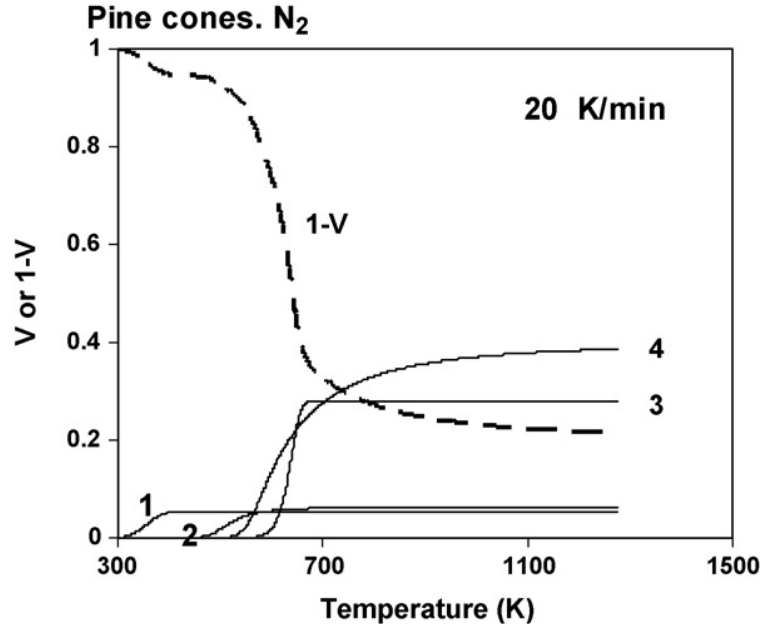

Fig. 10. Evolution of the mass fraction of volatiles for each reaction in a pine cone pyrolysis run.

order reactions: $100 \mathrm{~kJ} / \mathrm{mol}$ for hemicellulose, $236 \mathrm{~kJ} / \mathrm{mol}$ for cellulose and $46 \mathrm{~kJ} / \mathrm{mol}$ for lignin. Note the low value of the apparent activation energy of lignin in comparison with the hemicellulose and cellulose. Nevertheless, when many fractions of lignin are considered in the decomposition, values of activation energy between $72.4 \mathrm{~kJ} / \mathrm{mol}$ at $200{ }^{\circ} \mathrm{C}$ to $174 \mathrm{~kJ} / \mathrm{mol}$ at $700{ }^{\circ} \mathrm{C}$ are obtained [20].

During the optimization process, we observed that the fitting of a broad peak, i.e. taking place from very low to very high temperatures, such as that of lignin, could be done by the combination of low reaction orders and very low activation energies and also with high reaction order, and high activation energies, as can be tested from the correlation of the data. The values proposed are the optimized ones that lead to the best possible correlation.

Reaction orders greater than unity can be justified when the specific surface of decomposition decreases with the conversion [21].

For the pyrolysis of pine needles, a fifth fraction with a very small evolved volume of volatiles has been considered in order to correlate the DTG data obtained.

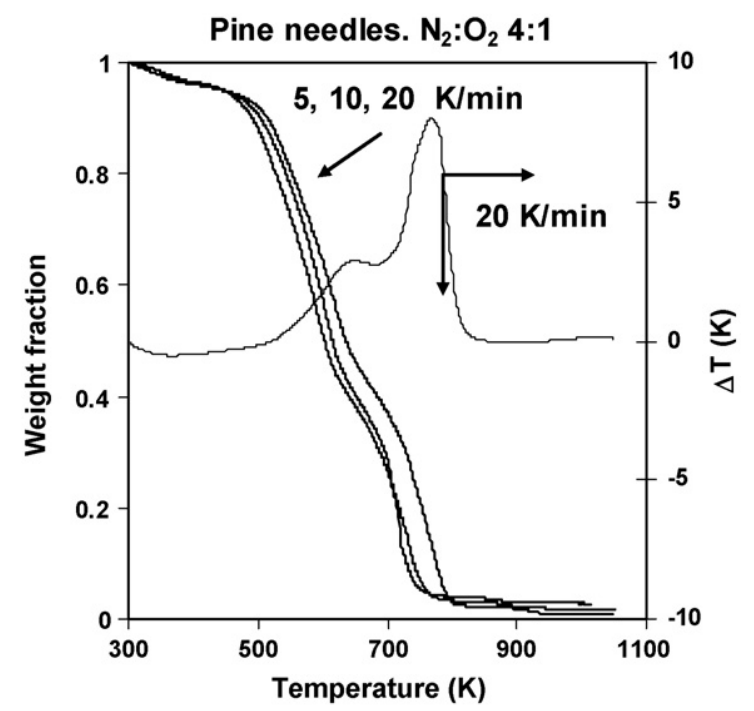

Fig. 11. Pine needle combustion at 5,10 and $20 \mathrm{~K} \mathrm{~min}^{-1}$. Experimental curves (the calculated curves overlap the experimental ones).
Pine needles $\mathrm{N}_{2}: \mathrm{O}_{2} 4: 1$

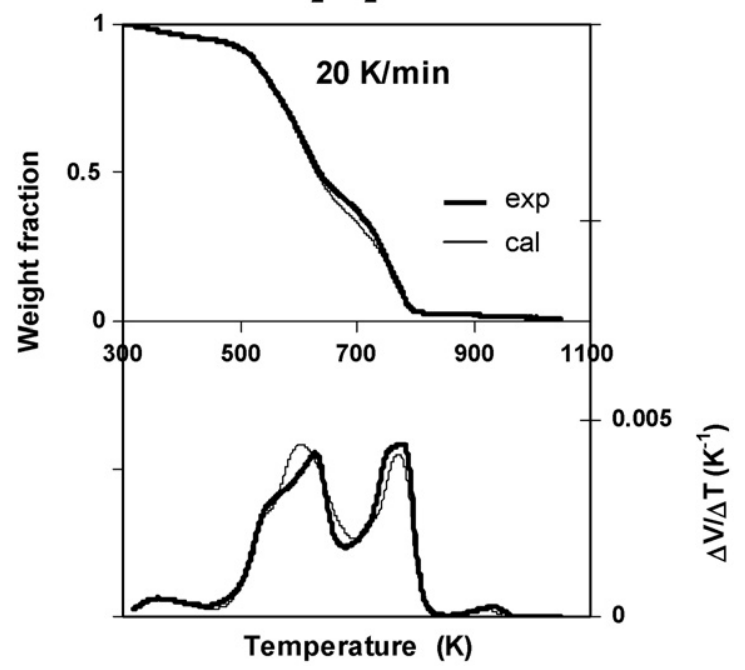

Fig. 12. Weight fraction and its derivative from a pine needle combustion run.

Figs. 9 and 10 show the calculated variation of the volatiles corresponding to different fractions considered: 1 (mainly humidity), 2 (mainly hemicellulose), 3 (mainly cellulose) and 4 (mainly lignin).

\section{Oxidative pyrolysis and combustion: results and discussion}

\subsection{Experimental results}

Fig. 11 shows the experimental TG plots for pine needle combustion $\left(\mathrm{N}_{2}: \mathrm{O}_{2} 4: 1\right)$ at heating rates of 5,10 and $20 \mathrm{~K} \mathrm{~min}^{-1}$. The value of increment of temperature, corresponding to the DTA, for a run is also plotted in a logical scale, from $-10 \mathrm{~K}$ to $10 \mathrm{~K}$ It can be observed that there is only a light endothermic process at the first part of sample, due to the vaporization of humidity, then a moderate increase in the temperature corresponding to light exothermic process, and finally a considerable increase corresponding to a combustion process.

Fig. 12 shows the DTG curve for a combustion of pine needles in an $\mathrm{N}_{2}: \mathrm{O}_{2} 4: 1$ atmosphere, in order to observe the fractions that can be considered in the decomposition of the sample. It can be deduced that there is at least one initial peak (due to the

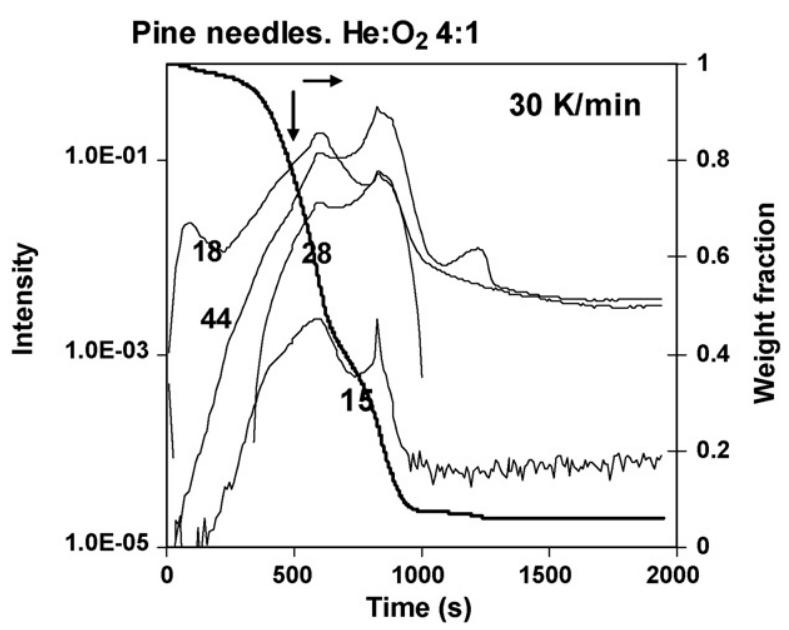

Fig. 13. Intensities of the ions $15\left(\mathrm{CH}_{4}\right), 18\left(\mathrm{H}_{2} \mathrm{O}\right), 28(\mathrm{CO})$ and $44\left(\mathrm{CO}_{2}\right)$ in a pyrolysis TG-MS run (He: $\mathrm{O}_{2}$ atmosphere) of pine needles. 


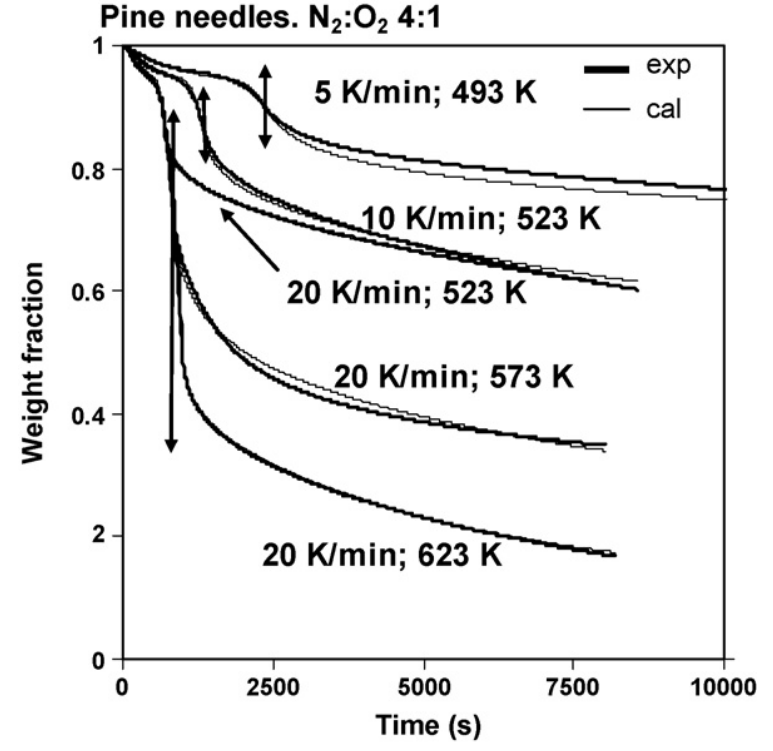

Fig. 14. Isothermal pine needle combustion. Experimental and calculated curves.

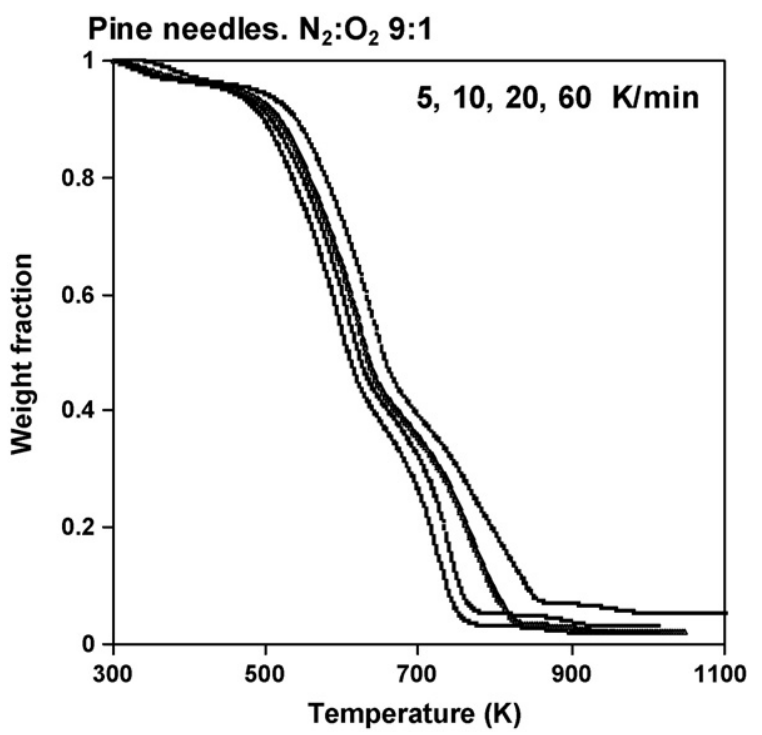

Fig. 15. Dynamic runs of oxidative pyrolysis $\left(\mathrm{N}_{2}: \mathrm{O}_{2}\right.$ 9:1) of pine needles at four heating rates.

vaporization of humidity), a band sum of two peaks, a fourth peak and finally a very small fifth peak.

Fig. 13 shows the intensities of some ions in the MS-TG run of pine needles ( $\left.\mathrm{He}: \mathrm{O}_{2} 4: 1\right)$ corresponding to $\mathrm{H}_{2} \mathrm{O}(\mathrm{m}+18), \mathrm{CO}_{2}(\mathrm{~m}+$ 44), $\mathrm{CO}(\mathrm{m}+28)$ and $\mathrm{CH}_{4}(\mathrm{~m}+15)$. The variation of the weight loss can also be observed. For the water, there is an initial peak (due to the humidity of the sample), and then a wide band with two peaks, coinciding with $\mathrm{CO}, \mathrm{CO}_{2}$ and $\mathrm{CH}_{4}$, indicating reactions of decomposition and oxidation. There is a final peak of $\mathrm{CO}_{2}$ probably corresponding to the de-carboxilation of a small fraction that decomposes at high temperature.

Five isothermal experiments were carried out for the combustion of pine needles at 5,10 and $20 \mathrm{~K} / \mathrm{min}$ under an atmosphere of $\mathrm{N}_{2}: \mathrm{O}_{2} 4: 1$ between 493 and $623 \mathrm{~K}$ (Fig. 14). It can also be observed that the final residue mass fraction depends on the operating conditions.
Pine needles: $\mathrm{N}_{2}: \mathrm{O}_{2}$ 9:1

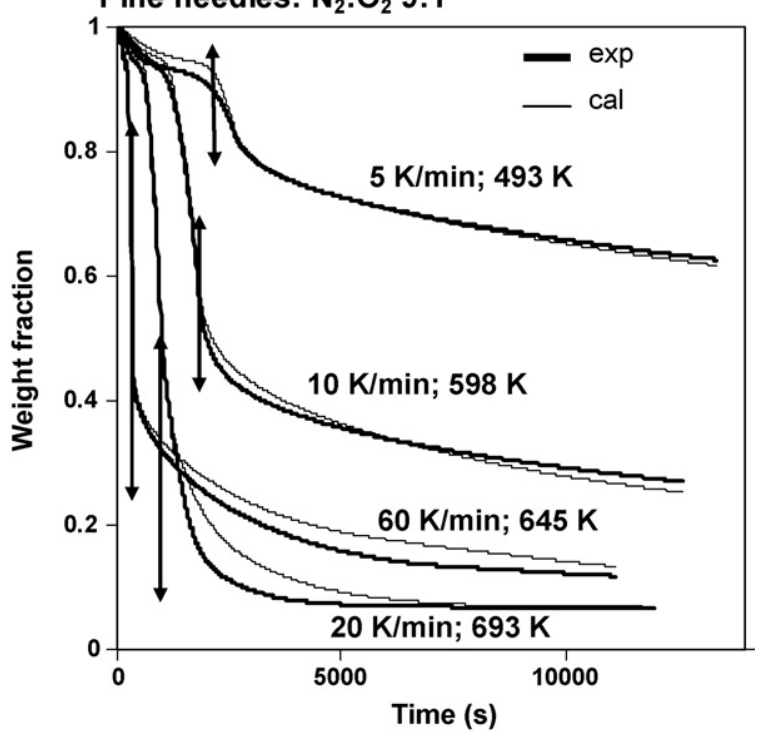

Fig. 16. Isothermal runs in a $\mathrm{N}_{2}: \mathrm{O}_{2} 9: 1$ atmosphere of pine needles at different operating conditions.

Figs. 15 and 16 show the variation corresponding to four dynamic runs and four isothermal runs carried out in an $\mathrm{N}_{2}: \mathrm{O}_{2} 9: 1$ atmosphere with pine needles. The shapes of the curves corresponding to the dynamic runs are similar to those carried out at $\mathrm{N}_{2}: \mathrm{O}_{2} 4: 1$ atmosphere, although a slight displacement of the last portion of the curves to higher temperatures could be observed when plotting all the results in the same graph. This is a consequence of a decrease of the decomposition rate at lower oxygen pressure.

A similar experimental programme was carried out with pine cones: three dynamic runs with DTA in $\mathrm{N}_{2}: \mathrm{O}_{2} 4: 1$ atmosphere (Fig. 17), a TG-MS run with $\mathrm{He}: \mathrm{O}_{2} 4: 1$ to observe the evolution of $\mathrm{CO}, \mathrm{CO}_{2}, \mathrm{CH}_{4}$ and $\mathrm{H}_{2} \mathrm{O}$ (Fig. 18), four isothermal runs in $\mathrm{N}_{2}: \mathrm{O}_{2} 4: 1$ atmosphere (Fig. 19), four dynamic runs in an $\mathrm{N}_{2}: \mathrm{O}_{2}$ 9:1 atmosphere (Fig. 20), a dynamic run, both TG and DTG in an $\mathrm{N}_{2}: \mathrm{O}_{2}$ 9:1 atmosphere (Fig. 21) and four isothermal runs in $\mathrm{N}_{2}: \mathrm{O}_{2}$ 9:1 atmosphere (Fig. 22). Similar conclusions to those deduced from the pine needles can be established. Figs. 23 and 24 show the

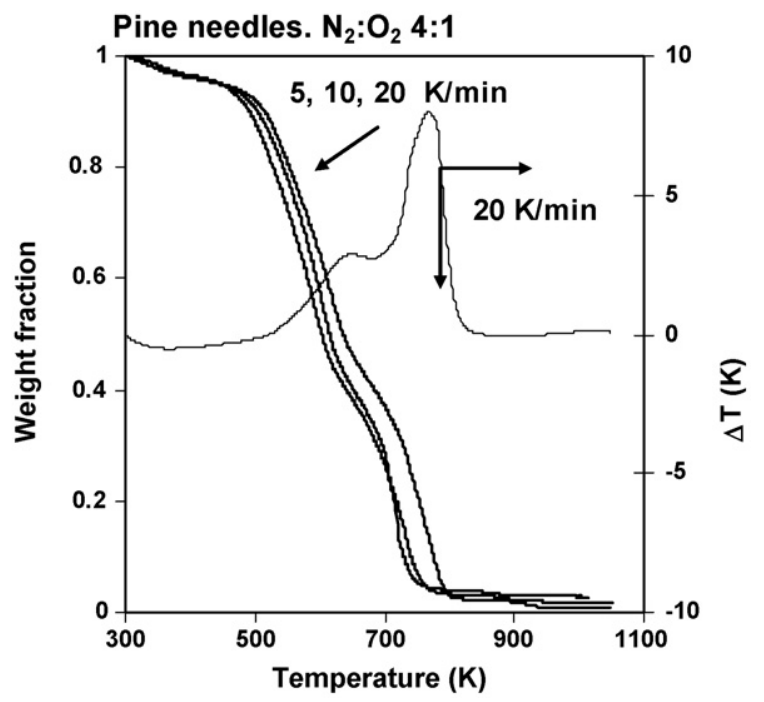

Fig. 17. Pine cones combustion at 5,10 and $20 \mathrm{~K} \mathrm{~min}^{-1}$. Experimental curves (the calculated curves overlap the experimental ones). 
Pine cones. $\mathrm{He}: \mathrm{O}_{2} 4: 1$

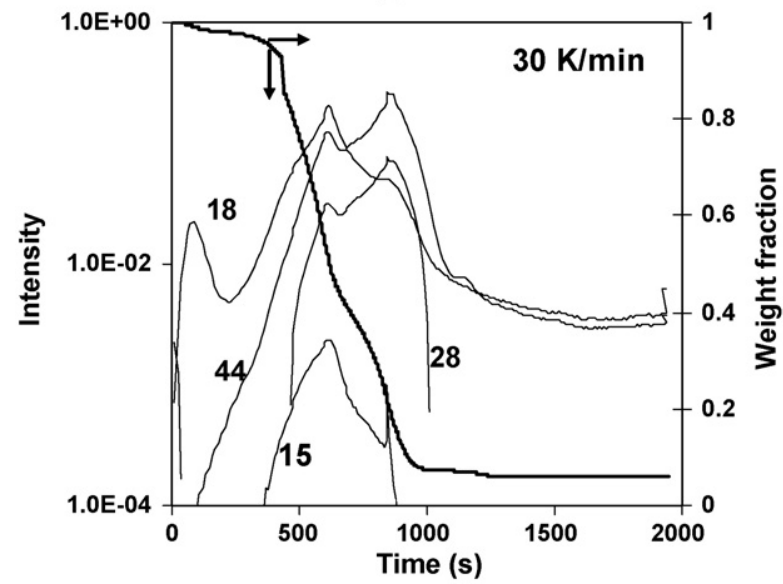

Fig. 18. Intensities of the ions $15\left(\mathrm{CH}_{4}\right), 18\left(\mathrm{H}_{2} \mathrm{O}\right), 28(\mathrm{CO})$ and $44\left(\mathrm{CO}_{2}\right)$ in a combustion TG-MS run (He: $\mathrm{O}_{2}$ atmosphere) of pine cones.

variation of the volatiles evolved corresponding to the complex scheme of reactions.

\subsection{Combustion model}

The combustion model proposed to explain the thermal decomposition of both materials is shown in the following scheme:

Pyrolysis reactions:

$$
\begin{aligned}
& w_{s_{10}} \text { Solid }_{1} \stackrel{1}{\longrightarrow}\left(w_{s_{10}}-v_{1 \infty}\right) \text { Char }_{1}+v_{1 \infty} \text { Volatiles }_{1} \\
& w_{s_{20}} \text { Solid }_{2} \stackrel{2}{\longrightarrow}\left(w_{s_{20}}-v_{2 \infty}\right) \text { Char }_{2}+v_{2 \infty} \text { Volatiles }_{2} \\
& w_{s_{30}} \text { Solid }_{3} \stackrel{3}{\longrightarrow}\left(w_{s_{30}}-v_{3 \infty}\right) \text { Char }_{3}+v_{3 \infty} \text { Volatiles }_{3} \\
& w_{s_{40}} \text { Solid }_{4} \stackrel{4}{\longrightarrow}\left(w_{s_{40}}-v_{4 \infty}\right) \text { Char }_{4}+v_{4 \infty} \text { Volatiles }_{4}
\end{aligned}
$$

(only for pine needles)

Combustion of char for reactions 3 and 4:

$$
\begin{aligned}
& \left(w_{\mathrm{s}_{30}}-v_{3 \infty}\right) \text { Char }_{3}+\left(\mathrm{O}_{2}\right) \stackrel{3 \mathrm{c}}{\longrightarrow} v_{3 \mathrm{c} \infty} \text { Volatiles }_{3 \mathrm{c}} \\
& \quad+\left(w_{\mathrm{s}_{30}}-v_{3 \infty}-v_{3 \mathrm{c} \infty}\right) \mathrm{Ash}_{3 \mathrm{c}} \\
& \left(w_{\mathrm{s}_{40}}-v_{4 \infty}\right) \operatorname{Char}_{4}+\left(\mathrm{O}_{2}\right) \stackrel{4 \mathrm{c}}{\longrightarrow} v_{4 \mathrm{c} \infty} \text { Volatiles }_{4 \mathrm{c}} \\
& \quad+\left(w_{\mathrm{s}_{40}}-v_{4 \infty}-v_{4 \mathrm{c} \infty}\right) \operatorname{Ash}_{4 \mathrm{c}}
\end{aligned}
$$

Pine cones. $\mathrm{N}_{2}: \mathrm{O}_{2} 4: 1$

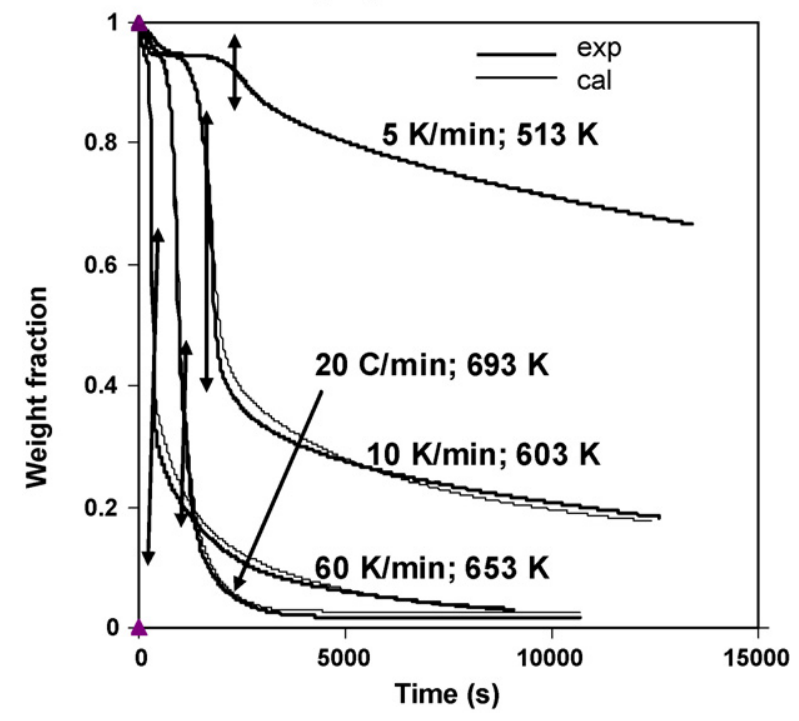

Fig. 19. Isothermal runs in a $\mathrm{N}_{2}: \mathrm{O}_{2} 9: 1$ atmosphere of pine cones.
Pine cones. $\mathrm{N}_{2}: \mathrm{O}_{2}$ 9:1

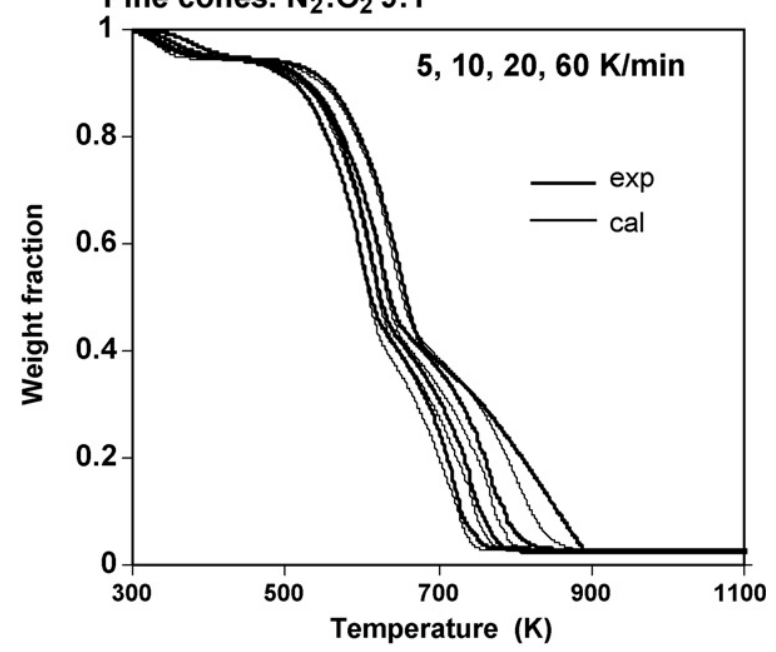

Fig. 20. Dynamic runs of pine cones in a $\mathrm{N}_{2}: \mathrm{O}_{2}$ 9:1 atmosphere.

Competitive oxidative pyrolysis reactions 3 and 4:

$w_{\mathrm{s}_{30}}$ Solid $_{3}+\left(\mathrm{O}_{2}\right) \stackrel{3 \mathrm{cp}}{\longrightarrow} v_{3 \mathrm{cp} \infty}$ Volatiles $_{3 \mathrm{cp}}+\left(w_{\mathrm{s}_{30}}-v_{3 \mathrm{cp} \infty}\right)$ Ash $_{3 \mathrm{cp}}$ $w_{\mathrm{s}_{40}}$ Solid $_{4}+\left(\mathrm{O}_{2}\right) \stackrel{4 \mathrm{cp}}{\longrightarrow} v_{4 \mathrm{cp} \infty}$ Volatiles $_{4 \mathrm{cp}}+\left(w_{\mathrm{s}_{40}}-v_{4 \mathrm{cp} \infty}\right)$ Ash $_{4 \mathrm{cp}}$

Reaction of a minor fraction

$w_{\mathrm{s}_{50}}$ Solid $_{5} \stackrel{5}{\longrightarrow}\left(w_{\mathrm{s}_{50}}-v_{5 \infty}\right) \mathrm{Ash}_{5}$

$+v_{5 \infty}$ Volatiles $_{5} \quad$ (only for pine needles)

In the previous equations, the values of volatile fractions are related to the initial mass of solid so, logically, the real amount of volatiles corresponding to the oxidation reactions is greater, but it cannot be measured in the TG runs.

This scheme has been proposed after analysing the results with other schemes with different number of reactions, and considering the shape of the curves presented previously.

In this model, it has been considered that in the combustion reactions, the reaction rate is proportional to the oxygen pressure, whereas in the competitive oxidative pyrolysis $3 \mathrm{cp}$ and $4 \mathrm{cp}$, the reaction rate does not depend on the oxygen pressure. These conclusions have been obtained from the best correlation of the data.

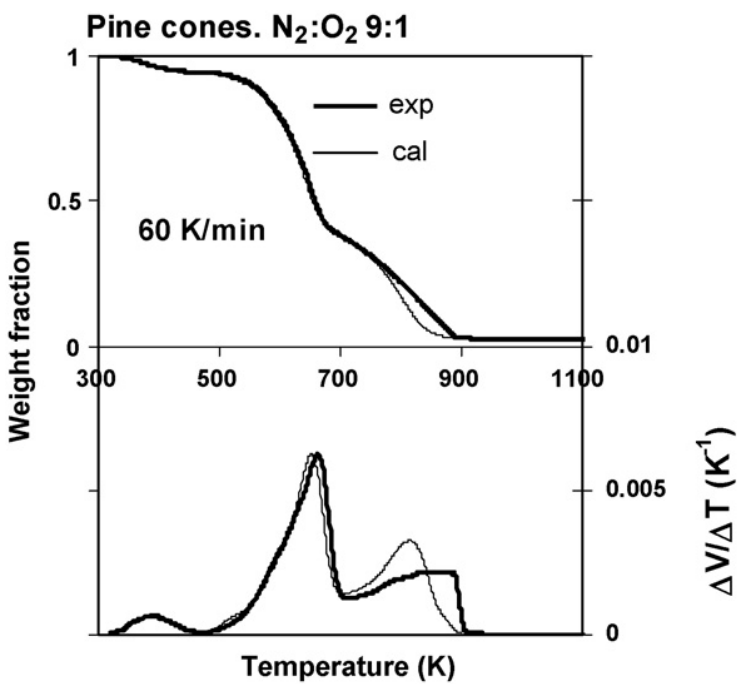

Fig. 21. Weight fraction and its derivative with respect to temperature in a $\mathrm{N}_{2}: \mathrm{O}_{2}$ ratio run of pine cones. 
Pine cones. $\mathrm{N}_{2}: \mathrm{O}_{2} 9: 1$

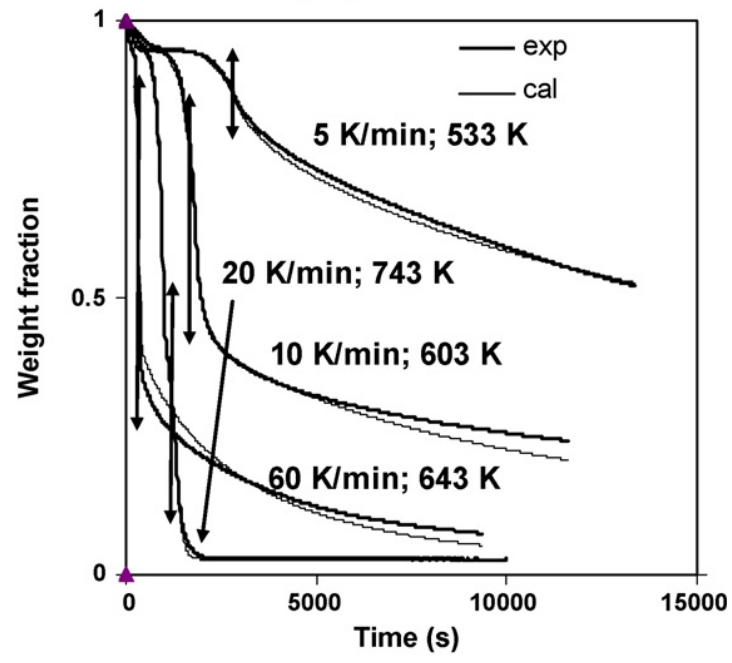

Fig. 22. Isothermal runs in a $\mathrm{N}_{2}: \mathrm{O}_{2} 9: 1$ atmosphere of pine cones.

The kinetic equations, considering degree conversions are the following:

$\frac{\mathrm{d} \alpha_{i}}{\mathrm{~d} t}=k_{i}\left(1-\alpha_{i}\right)^{n_{i}}, \quad$ for $i=1,2$ and 5

$\frac{\mathrm{d} \alpha_{\mathrm{i}}}{\mathrm{d} t}=k_{i}\left(1-\alpha_{i}-\alpha_{i \mathrm{cp}}\right)^{n_{i}}, \quad$ for $i=3,4$

$\frac{\mathrm{d} \alpha_{i \mathrm{cp}}}{\mathrm{d} t}=k_{i \mathrm{cp}}\left(1-\alpha_{i}-\alpha_{i \mathrm{cp}}\right)^{n_{\mathrm{ipoi}}}, \quad$ for $i \mathrm{cp}=3 \mathrm{cp}, 4 \mathrm{cp}$

Note that the reactions 3 and $3 \mathrm{cp}$ and 4 and $4 \mathrm{cp}$ are competitive. On the other hand, there are also two consecutive reactions as a consequence of the burning of the char residue, so

$\frac{\mathrm{d} \alpha_{i \mathrm{c}}}{\mathrm{d} t}=k_{i \mathrm{c}}\left(\alpha_{i}-\alpha_{i \mathrm{c}}\right)^{n_{\mathrm{ic}}}, \quad$ for $i \mathrm{c}=3 \mathrm{c}, 4 \mathrm{c}$

where the pre-exponential factor $k_{\text {ic }}$ is directly proportional to the oxygen pressure, and can be written as

$k_{i c}=k_{i c}^{*} \frac{p_{\mathrm{O}_{2}}}{0.20} \quad\left(p_{\mathrm{O}_{2}}\right.$ in atm $)$

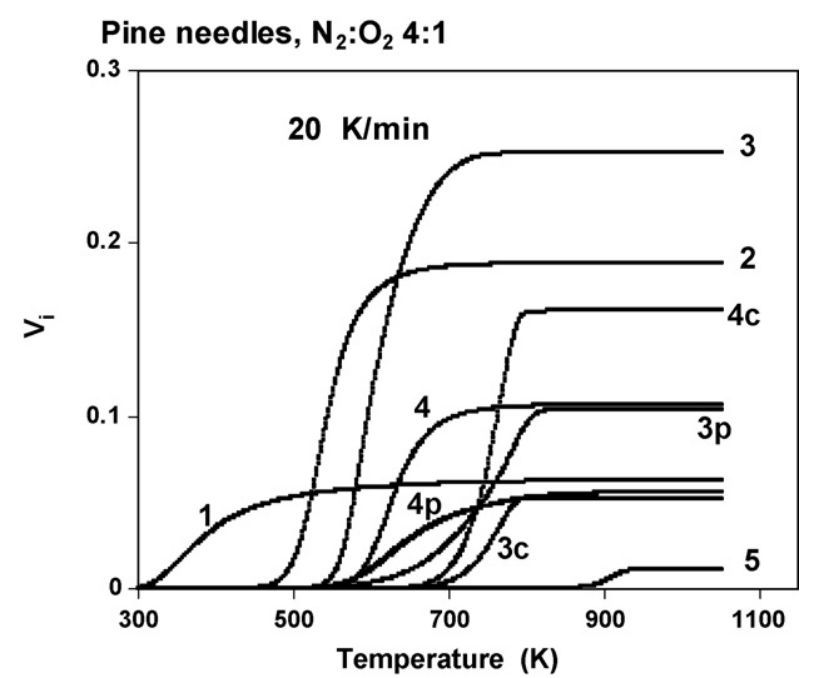

Fig. 23. Evolution of the mass fraction of volatiles for each reaction in a pine needle combustion run.
Pine cones. $\mathrm{N}_{2}: \mathrm{O}_{2} 4: 1$

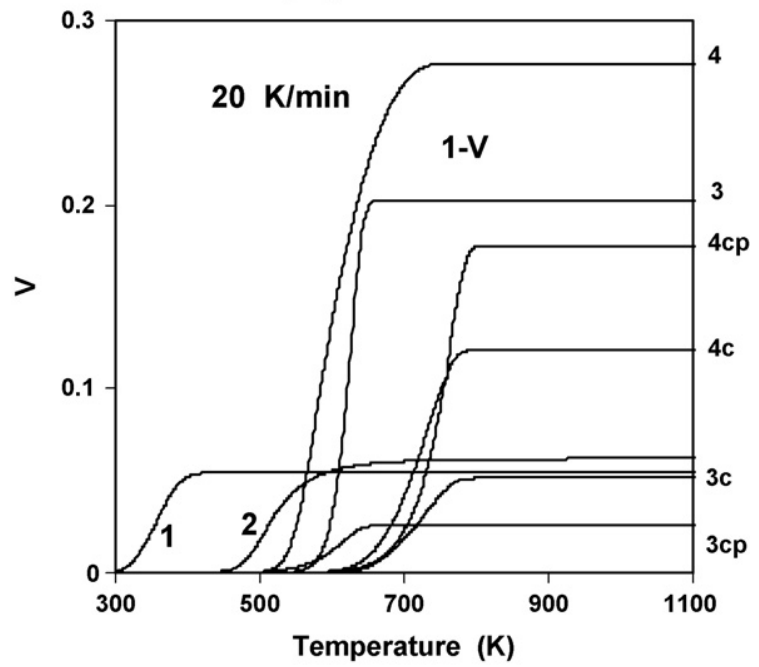

Fig. 24. Evolution of the mass fraction of volatiles for each reaction in a pine cone combustion run.

where $p_{\mathrm{O}_{2}}$ is the partial pressure of oxygen in atm, and logically $k_{\text {ic }}$ equals $k_{i c}^{*}$ when working with $\mathrm{N}_{2}: \mathrm{O}_{2} 4: 1$ atmosphere $\left(p_{\mathrm{O}_{2}}\right.$ equals $0.20 \mathrm{~atm})$.

The total weight fraction and the volatile weight fraction $V$ are related to the conversion degrees by

$$
\begin{aligned}
w= & 1-V \\
= & 1-\left(v_{1 \infty} \alpha_{1}+v_{2 \infty} \alpha_{2}+v_{3 \infty} \alpha_{3}+v_{4 \infty} \alpha_{4}+v_{5 \infty} \alpha_{5}\right. \\
& \left.+v_{3 \mathrm{cp} \infty} \alpha_{3 \mathrm{po}}+v_{4 \mathrm{cp} \infty} \alpha_{4 \mathrm{po}}+v_{3 c \infty} \alpha_{c 3}+v_{4 c \infty} \alpha_{c 4}\right)
\end{aligned}
$$

where $v_{i \infty}, v_{i c \infty}$ and $v_{\text {icp } \infty}$ represent the maximum value of volatiles with the corresponding reaction without possible competence with other reactions, and coincide with the corresponding yield coefficients.

\subsection{Kinetic parameters}

In order to obtain a single set of parameters for the combustion of each material, the dynamic runs and the isothermal runs were correlated to the same set of parameters by a similar procedure explained with the correlation of the pyrolysis data. It has been considered that the reactions 1 and 2 take place under $600 \mathrm{~K}$, so the kinetic parameters are equal to those obtained from the correlation of the pyrolysis data, due to the fact that the effect of the oxygen is probably negligible.

For the fractions 3 and 4 , the pyrolytic reactions 3 and 4 have the same values of apparent activation energy and reaction order as the reactions 3 and 4 under nitrogen atmosphere, but it has been considered that the pre-exponential factor could change due the presence of the oxygen, in addition to the competitive oxidative pyrolysis reactions $3 c$ and $4 c$, due to the possible new routes of oxidation (the presence of the competitive reactions can also justify that the pre-exponential factors of the reactions 3 and 4 are different from those under strict pyrolysis conditions, because new decomposition centres can appear with the competitive reactions). With all these considerations, acceptable correlations of the data are obtained.

Table 3 shows the set of parameters optimized for both wastes. The calculated curve variations are also plotted in some figures shown previously, when the overlapping does not impede a good comparison. It can be deduced that the correlations are quite good. 
Table 3

Kinetic parameters obtained for the combustion of pine needles and pine cones $\left(k_{i o}\right.$ and $k_{i}$ in $\mathrm{s}^{-1}$ and $E_{i}$ in $\mathrm{kJ} \mathrm{mol}^{-1}$ ).

\begin{tabular}{|c|c|c|}
\hline & Pine needle & Pine cone \\
\hline \multicolumn{3}{|c|}{ Pyrolytic reactions } \\
\hline$V_{1}$ & 0.06 & 0.05 \\
\hline$k_{1 \mathrm{o}}$ & $1.985 E+04$ & $3.053 E+04$ \\
\hline$E_{1}$ & 43.07 & 43.54 \\
\hline$n_{1}$ & 4.20 & 1.30 \\
\hline$V_{2}$ & 0.19 & 0.06 \\
\hline$k_{20}$ & $5.838 \mathrm{E}+11$ & $8.500 \mathrm{E}+11$ \\
\hline$E_{2}$ & 137.18 & 132.36 \\
\hline$n_{2}$ & 2.89 & 3.70 \\
\hline$V_{3}$ & 0.34 & 0.22 \\
\hline$k_{30}$ & $1.38 \mathrm{E}+19$ & $2.108 \mathrm{E}+15$ \\
\hline$E_{3}$ & 233.32 & 203.39 \\
\hline$n_{3}$ & 7.73 & 1.13 \\
\hline$V_{4}$ & 0.13 & 0.40 \\
\hline$k_{40}$ & $8.99 E+14$ & $2.947 \mathrm{E}+15$ \\
\hline$E_{4}$ & 197.31 & 190.64 \\
\hline$n_{4}$ & 3.58 & 8.69 \\
\hline \multicolumn{3}{|c|}{ Combustion of char for reactions 3 and 4} \\
\hline$V_{3 c}$ & 0.07 & 0.06 \\
\hline$k_{3 \mathrm{c}}^{*}$ & $3.323 \mathrm{E}+09$ & $5.140 \mathrm{E}+04$ \\
\hline$E_{3 c}$ & 166.17 & 94.81 \\
\hline$n_{3 \mathrm{c}}$ & 0.91 & 0.91 \\
\hline$V_{4 \mathrm{c}}$ & 0.19 & 0.18 \\
\hline$k_{4 \mathrm{c}}^{*}$ & $3.323 \mathrm{E}+09$ & $5.140 \mathrm{E}+04$ \\
\hline$E_{4 \mathrm{c}}$ & 166.17 & 94.81 \\
\hline$n_{4 \mathrm{c}}$ & 0.91 & 0.91 \\
\hline \multicolumn{3}{|c|}{ Competitive oxidative pyrolysis reactions 3 and 4} \\
\hline$V_{3 \mathrm{cp}}$ & 0.41 & 0.28 \\
\hline$k_{3 \mathrm{cp}}$ & $1.065 \mathrm{E}+03$ & $6.545 \mathrm{E}+02$ \\
\hline$E_{3 \mathrm{cp}}$ & 80.69 & 71.00 \\
\hline$n_{3 \mathrm{cp}}$ & 0.66 & 0.71 \\
\hline$V_{4 \mathrm{cp}}$ & 0.32 & 0.58 \\
\hline$k_{4 \mathrm{cp}}$ & $1.516 \mathrm{E}+05$ & $1.916 \mathrm{E}+07$ \\
\hline$E_{4 \mathrm{cp}}$ & 97.49 & 137.11 \\
\hline$n_{4 \mathrm{cp}}$ & 1.66 & 0.78 \\
\hline \multicolumn{3}{|c|}{ Reaction of a minor fraction } \\
\hline$V_{5 \mathrm{cp}}$ & 0.01 & \\
\hline$k_{5}$ & $1.596 \mathrm{E}+22$ & \\
\hline$E_{5}$ & 415.70 & \\
\hline$n_{5}$ & 1.00 & \\
\hline VC (\%) & 3.2 & 4.2 \\
\hline
\end{tabular}

In view of Table 3, some interesting aspects can be highlighted. The apparent activation energy obtained for the combustion of the char formed $(95-166 \mathrm{~kJ} / \mathrm{mol})$ can be compared with those obtained by other researchers. Haji-Sulaiman and Aroua [22] proposed values around $135 \mathrm{~kJ} / \mathrm{mol}$ for the oxidation of Malaysian coal chars. From the data presented by Henrich et al. [23], values of apparent activation energy around $140 \mathrm{~kJ} / \mathrm{mol}$ were proposed for

Table 4

Comparison between the values of volatile mass corresponding to different fractions and the content of the raw material.

\begin{tabular}{|c|c|c|c|c|}
\hline & \multicolumn{2}{|l|}{ Pine needles } & \multicolumn{2}{|l|}{ Pine cones } \\
\hline & $\begin{array}{l}\text { Content (\%) } \\
\text { on dry basis }\end{array}$ & $\begin{array}{l}\text { Volatile mass } \\
\text { percentage on } \\
\text { dry basis }\end{array}$ & $\begin{array}{l}\text { Content (\%) } \\
\text { on dry basis }\end{array}$ & $\begin{array}{l}\text { Volatile mass } \\
\text { percentage on } \\
\text { dry basis }\end{array}$ \\
\hline Ethanol extracts & 18.2 & & 7.3 & \\
\hline Hemicellulose & 17.7 & 19 & 21.7 & 6 \\
\hline Cellulose & 38.7 & 42 & 39.3 & 30 \\
\hline Lignin & 20.1 & 32 & 30.9 & 58 \\
\hline
\end{tabular}

the oxidation in pure oxygen of soot, graphite, activated charcoals and chars from municipal waste and electronic scrap. Walker et al. [24] obtained apparent activation energy values around 209$242 \mathrm{~kJ} / \mathrm{mol}$ for the reaction: $\mathrm{C}+1 / 2 \mathrm{O}_{2} \rightarrow \mathrm{CO}$. The oxygen reaction order assumed in the present work for the combustion reactions is the unity, similar to that considered in the gasification of carbon [25]. The lower value of $95 \mathrm{~kJ} / \mathrm{mol}$ for the char combustion of pine cones could indicate an influence of the oxygen transfer inside the particles. On the other hand, the values of $V_{3 c}$ (char residue of the fraction associated mainly with cellulose) are small, in accordance with the residue obtained from cellulose.

Table 4 shows the mass fraction of hemicellulose, cellulose and lignin obtained from the analysis and from the correlation of the data, accepting that $V_{2}$ corresponds to hemicellulose, $V_{3 \text { cp }}$ or $V_{3}+V_{3 \mathrm{c}}$ corresponds to cellulose and $V_{4 \mathrm{p}}$ or $V_{4}+V_{4 \mathrm{c}}$ corresponds to lignin. It can be deduced that for pine needles the values of mass fractions are similar to those obtained from the correlation of the data, assuming that some important part of the ethanol extracts are included in the last fraction. For the pine cones, the fraction 4 is probably formed by lignin and other components. This variation of behavior can be found in the paper of Müller-Hagedorn and Bockhorn [26]. This means the real kinetic model, valid in an interval of operating conditions, must be obtained from the correlation of the data, and this is not an easy task when this interval of operating conditions is wide, as occurs in this paper.

\section{Analysis of the data obtained from the TG-MS data}

Figs. 3, 7, 13 and 18 show the variation of the intensity ions corresponding to water $(+18)$, carbon monoxide $(+28)$, carbon dioxide $(+44)$ and methane $(+15)$ in a helium atmosphere or $4: 1$ $\mathrm{He}: \mathrm{O}_{2}$ atmosphere. The study carried out has been extensive considering the ions indicated in the experimental section. Considering all the graphs obtained, in addition to those presented, it can be outlined that there is a clear evolution of hydrocarbons (ethylene, acetylene, propylene) similar to that of methane, so these compounds are evolved in the pyrolysis and combustion of these materials (ions $25,26,27,39,40,41$ ). For the pyrolysis runs, the evolution of methane also takes place at high temperatures in the last part of the decomposition curve. Both pine materials have the same behavior.

Another similar behavior in the variation of intensities in pyrolysis is observed between the ion +44 , corresponding to the carbon dioxide and the ions 43,45 and 46 corresponding to oxygenated compounds (acetic acid, 2-propanol, hydroxyacetone, propionic acid, formic acid, etc.) This indicates that the decarboxylation process is parallel to the evolution of oxygenated compounds.

\section{Conclusions}

A kinetic model for the pyrolysis and combustion of pine needles and pine cones has been obtained, for correlating dynamic and isothermal runs with the same set of parameters. There are three main fractions corresponding to hemicellulose, cellulose and lignin, but other small fractions have been also taken into account.

\section{Acknowledgment}

Support for this work was provided by Spanish MEC, research project CTQ2005-05262.

\section{References}

[1] S.E. Liodakis, M.K. Statheropoulos, N.E. Tzamtzis, A.A. Pappa, G.K. Parissakis, Thermochim. Acta 278 (1996) 99. 
[2] A. Pappa, K. Mikedi, N. Tzamtzis, M. Statheropoulos, J. Therm. Anal. Calorim. 84 (2006) 655.

[3] M. Statheropoulos, S. Liodakis, N. Tzamtzis, A. Pappa, S. Kyriakou, J. Anal. Appl. Pyrol. 43 (1997) 115

[4] J.-G. Lee, C.-G. Lee, J.-J. Kwag, A.J. Buglass, G.-H. Lee, J. Chromatogr. A 1089 (2005)

[5] E. Leoni, P. Tomi, B. Khoumeri, N. Blabi, J. Fire Sci. 19 (2001) 379.

[6] O. Senneca, Fuel Process. Technol. 88 (2007) 87.

[7] H. Haykiri-Acma, S. Yaman, Fuel Process. Technol. 88 (2007) 417.

[8] E. Leoni, D. Cancellieri, N. Balbi, A.F. Bernardini, J. Kaloustian, T. Marcelli, J. Fire Sci. 21 (2003) 117

[9] R.R. Rowell, R.A. Young, J. Rowell (Eds.), Paper and Composites from Agro-Based Resources. Chap. 3. Analytical Procedures, CRC Press, 1996.

[10] Technical Association for the Pulp and Paper Industries (TAPPI), Preparation of extractive free-wood. TAPPI Test Method T 12 os-75. TAPPI PRESS, Atlanta, 1978

[11] Technical Association for the Pulp and Paper Industries (TAPPI), Acid-insoluble in wood and pulp. TAPPI Test Method T 222 os-74. TAPPI PRESS, Atlanta, 1978.

[12] Technical Association for the Pulp and Paper Industries (TAPPI), Alpha-, Beta- and Gamma Cellulose in pulp. TAPPI Test Method T 203 os-74. TAPPI PRESS, Atlanta, 1978.
[13] M. Grønli, M.J. Antal, G. Várhegyi, Ind. Eng. Chem. Res. 38 (1999) 2238

[14] I. Martín-Gullón, M.F. Gómez-Rico, A. Fullana, R. Font, J. Anal. Appl. Pyrol. 68-69 (2003) 645

[15] R. Font, A. Marcilla, E. Verdú, J. Devesa, J. Anal. Appl. Pyrol. 21 (1991) 249.

[16] M.J. Antal Jr., H.L. Friedman, F.E. Rogers, Combust. Sci. Technol. 21 (1980) 141.

[17] M.J. Antal Jr., G. Varhegyi, Ind. Eng. Chem. Res. 34 (1995) 703.

[18] I. Milosavljevic, E.M. Suuberg, Ind. Eng. Chem. Res. 34 (1995 1081).

[19] M.G. Grønly, G. Várhegyi, C. Di Blasi, Ind. Eng. Chem. Res. 41 (17) (2002) 4201.

[20] J.A. Caballero, R. Font, A. Marcilla, A.N. García, Ind. Eng. Chem. Res. 34 (3) (1995) 806.

[21] R. Font, A. García, J. Anal. Appl. Pyrol. 35 (1995) 249.

[22] M.Z. Haji-Sulaiman, M.K. Aroua, J. Inst. Energy 70 (1997) 52.

[23] E. Henrich, S. Bürkle, Z.I. Meza-Renken, S. Rumpel, J. Anal. Appl. Pyrol. 9 (1999) 133.

[24] P.L. Walker, F. Rusinko, L.G. Austin, Adv. Catal. 9 (1959) 133

[25] Z. Du, A.F. Sarofim, J.P. Longwell, J. Lahay, P. Ehrburger (Eds.), Fundamental Issues in Control of Carbon Gasification1992, p. 91

[26] M. Müller-Hagedorn, H. Bockhorn, J. Anal. Appl. Pyrolysis 79 (2007). 